\title{
Ultrasound Cycloplasty in Glaucoma - Mechanisms of Action and their Possible Impact on Intraocular Pressure
}

\author{
Kin Sheng Lim \\ Ophthalmology Department at St Thomas' Hospital, London, UK
}

U Itrasound cycloplasty (UCP) is a procedure based on high-intensity focused ultrasound (HIFU) for refractory and non-refractory glaucoma in cases for which surgery is not suitable. UCP may bring about a reduction in intraocular pressure (IOP) via multiple mechanisms of action that result in a decrease in aqueous humour production and increase in aqueous humour evacuation. UCP appears to have a favourable safety profile compared with cyclo-destructive methods, with no phthisis bulbi, no induced cataract, and no persistent hypotony. In 103 patients with refractory and non-refractory glaucoma who underwent UCP, 94 (91\%) achieved an initial reduction in IOP, and in 65 patients (63.1\%), treatment success was achieved whereby the IOP remained low. However, in 22 patients (21.4\%), at 3 months, the IOP rose to near the original level, indicating treatment failure: 'early failure'. In the remaining 7 patients (6.8\%), a slow rise in IOP occurred over 6 months following the procedure: 'late failure'. The differences in IOP changes in these 94 patients may be in part explained by: (i) a reduction in the uveoscleral-transscleral openings in some patients, leading to an eventual rise in the initially decreased IOP; (ii) a possible re-epithelialisation of the ciliary processes taking place in some cases; and/or (iii) that the circumference of $160^{\circ} \mathrm{UCP}$ treatment might not be sufficient for all patients. The first 3 months following the UCP procedure are therefore critical since treatment success or failure is determined within this timeframe.

\section{Keywords}

Intraocular pressure (IOP), glaucoma, ciliary body, ultrasound cycloplasty (UCP), mechanism of action, high-intensity focused ultrasound (HIFU)

Disclosure: Kin Sheng Lim has received research funding from EYE TECH CARE and is a consultant for Alcon, Novartis, Ivantis and iSTAR. This study involves a review of the literature and did not involve any studies with human or animal subjects performed by any of the authors

Acknowledgements: Medical writing support including preparation of the drafts under the guidance of the author, was provided by Catherine Amey, Touch Medical Media.

Authorship: All named authors meet the International Committee of Medical Journal Editors (ICMJE) criteria for authorship of this manuscript, take responsibility for the integrity of the work as a whole, and have given final approval to the version to be published.

open Access: This article is published under the Creative Commons Attribution Noncommercial License, which permits any non-commercial use, distribution, adaptation and reproduction provided the original author(s) and source are given appropriate credit.

Received: 12 May 2017

Accepted: 5 June 2017

Citation: European Ophthalmic Review,

2017;11(1):35-9

Corresponding Author: Kin Sheng Lim Ophthalmology Department at St Thomas' Hospital Westminster Bridge Road, London, SE1 7EH, UK. E: shenglim@gmail.com

Support: The publication of this article was supported by EYE TECH CARE. The views and opinions expressed in the article are those of the author and not necessarily those of EYE TECH CARE.
High-intensity focused ultrasound (HIFU) was first used to treat brain pathologies, such as Parkinson's disease In the 1940s. ${ }^{1}$ HIFU was later used in the 1990s in ophthalmological practice to treat intraocular pressure (IOP), traumatic capsular tears, glaucoma, retinal detachment and vitreous haemorrhage..$^{2-7} \mathrm{HIFU}$ has been used to treat both benign and malignant lesions of various solid tumours, ${ }^{8,9}$ and its potential has been recognised to transform treatment for a spectrum of other serious medical conditions. ${ }^{10}$ Indeed, focused ultrasound is under research or has already received regulatory approval for over 50 medical conditions in Europe, the US and Asia. In total, more than 115,000 patients have been treated with focused ultrasound, within the fields of oncology, endocrine and brain disorders, and women's health, among others..$^{10}$ Ultrasound cycloplasty (UCP) as a HIFU procedure is CE marked for both refractory and non-refractory glaucoma, where surgery is unsuitable. This review will explore the likely mechanisms of action of UCP and the consequences of these mechanisms on IOP change in patients with glaucoma.

\section{Ultrasound cycloplasty and its mechanisms of action for its efficacy in glaucoma}

Several studies published on the UCP technique have mentioned its possible mechanisms of action, both on the reduction of the aqueous humour production and on aqueous humour evacuation increase, as will be discussed.

First mechanism of action - aqueous humour production decrease UCP (Figure 1) has been developed for selective and non-aggressive structural modification of the ciliary processes, with sparing of the adjacent structures.11-13 Unlike diode laser treatment, controlled thermal coagulation is facilitated with HIFU, enabling good targeting of the tissue to be treated as well as precise temperature control. Further, in contrast to cyclo-destructive methods, ultrasound treatment induces a remodelling of the ciliary body whereby epithelial cell layers are removed with preservation of the blood-aqueous barrier and no apparent explosion of ciliary processes (Figures 2 and 3). Scanning electron microscopy of vascular corrosion cast following UCP treatment shows interruption of ciliary body's and pars plana microvasculature (Figure 4) in the treated zone (untreated areas are intact). The iris, iris root, major and minor arterial iris circles appeared untouched. 
Figure 1: Ultrasound cycloplasty
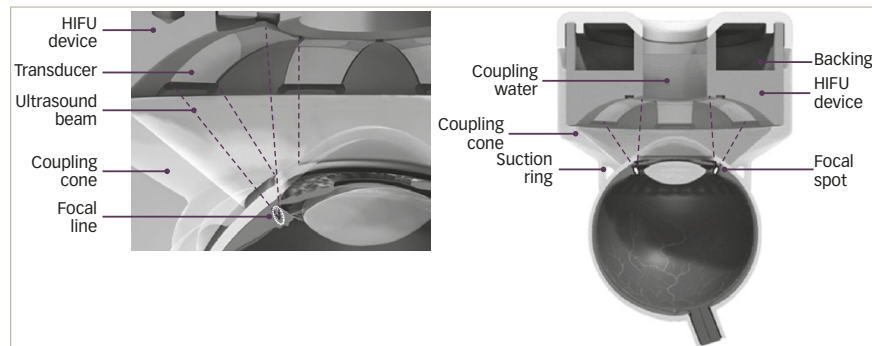

HIFU = high-intensity focused ultrasound. Reused with permission from EYE TECH CARE.

Figure 2: Untreated (top row) and treated (bottom row) areas of ciliary processes demonstrating remodelling of the ciliary body in rabbits
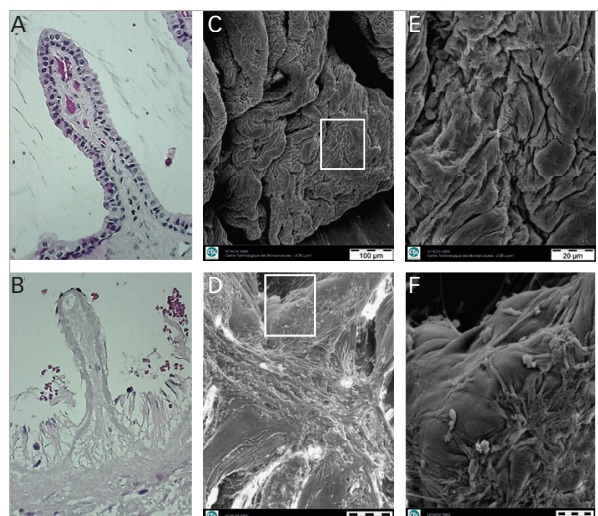

Untreated Ciliary Body.

Secretion of aqueous humor is made via epithelial cells.
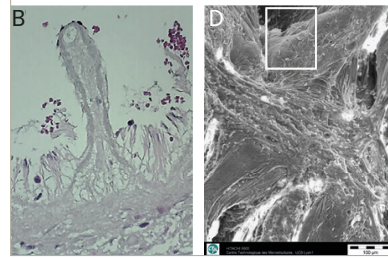

A and B: High-magnification (400 X) histological slices showing the ciliary processes in detail; C, D, E and F: Scanning electron microscopy (SEM) showing, in detail, the epithelium of rabbit's ciliary processes. Reused with permission from Aptel F et al. $2014 .^{2}$

Figure 5 depicts six visible treated zones in an experimental model pig eye that correspond to the six active transducers of the UCP probe. Modification of the ciliary body structure can be observed and the total surface area treated is less than $40 \%$ of that of the ciliary body. The ciliary body is treated over an angle of around $160^{\circ}$. Hence, UCP is a precise and non-aggressive procedure, allowing re-treatment if necessary to achieve the desired IOP reduction. Further, compared with traditional cyclodestructive methods of transscleral cyclophotocoagulation (TSCPC), ultrasound absorption does not depend on the individual pigmentation, and as such, energy deposition is much better controlled. Ultrasound can be used to heat and treat a well-defined and adjustable tissue volume at any depth or location. This slower temperature rise with UCP eliminates the risks of tissue explosion as can occur with diode laser treatment (Figure 3). This gradual process involving the ciliary body can be observed upon endoscopic video evidence (Figure 6). Temperature variability is also much more tightly controlled with UCP; thermal modelling of tissue behaviour shows that, depending on pigmentation for the same power, the temperature in diode laser treatment can vary from $60^{\circ} \mathrm{C}$ to more than $100^{\circ} \mathrm{C}$, whereas $\mathrm{UCP}$ treatment shows smaller temperature variation between $70^{\circ}$ and $80^{\circ} \mathrm{C}$ (Figure 7).

\section{Second mechanism of action - increase in aqueous outflow via uveoscleral pathway}

First reported by Bill in 1965, 14,15 an unconventional route for aqueous humour outflow has been described that includes the ciliary muscle, supraciliary and suprachoroidal spaces. Unconventional outflow may drain via: (i) a uveoscleral pathway whereby aqueous humour passes
Figure 3: Transscleral diode laser cyclophotocoagulation (A) versus ultrasound cycloplasty (B)
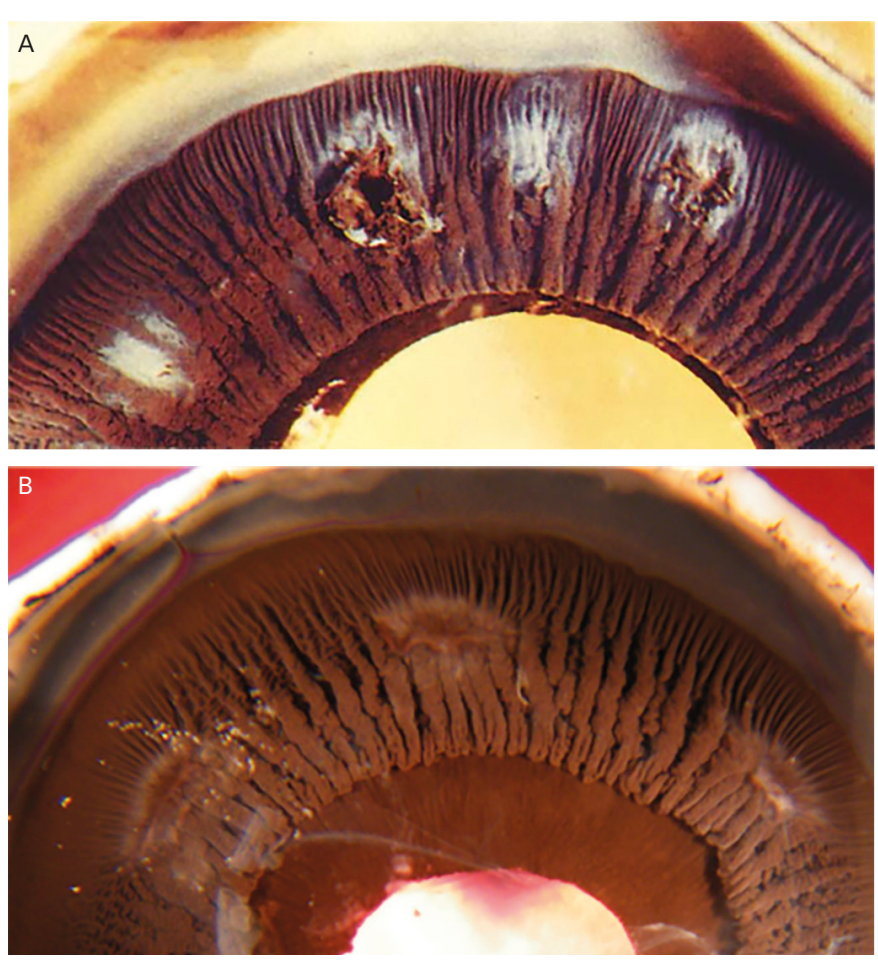

Reused with permission from Dürr $U$ et al., 1990. ${ }^{36}$

Figure 4: Low-magnification scanning electron microscopy images of rabbit's eye vascular corrosion
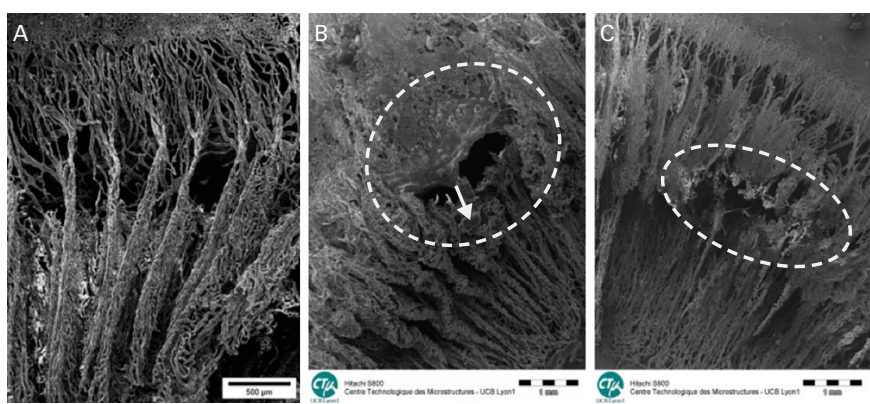

Untreated eye (A) and a treated eye (B and $C$ ). The ultrasound cycloplasty procedure coagulates microvessels to reduce aqueous humour secretion, without breaking the aqueous-humour barrier. Reused with permission from EYE TECH CARE.

Figure 5: Visualisation of the ciliary crown of a pig
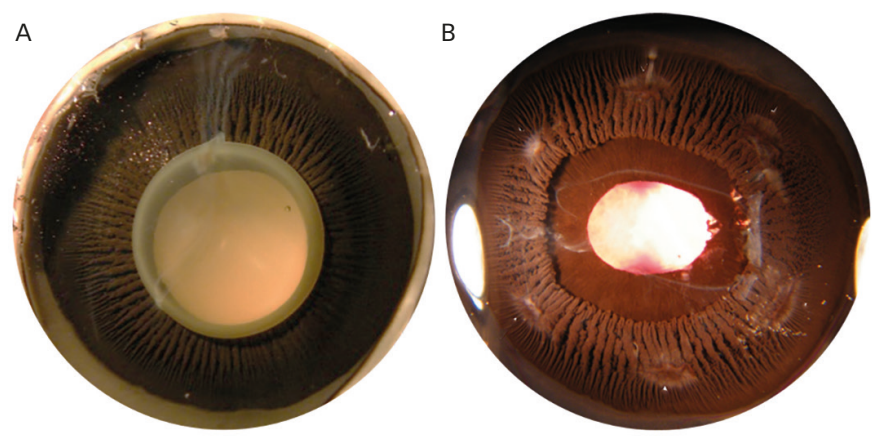

A: control; B: having undergone treatment with the ultrasound cycloplasty procedure (UCP) showing the six treatment zones (white arrows) corresponding to the six active transducers of the UCP probe. Reused with permission from EYE TECH CARE. 
across the sclera where it is resorbed by orbital vessels; and (ii) a uveovortex pathway where the aqueous drains via the choroid, through the vortex veins. ${ }^{16}$ The route of uveoscleral outflow is anatomically ill defined and its flow rate is relatively independent of pressure. ${ }^{17}$ The latter may be due to the fact that IOP changes do not have major impact on the pressure gradient for flow through the ciliary muscle, which is likely to be the rate-limiting step in uveoscleral outflow. ${ }^{18}$ It has been suggested that around $15 \%$ of aqueous humour outflow in human eyes is via uveoscleral routes; ${ }^{19}$ although, the relative proportion of aqueous humour draining from this route is controversial and appears to decrease with aging. ${ }^{20}$ There are no direct, non-invasive methods for determining uveoscleral outflow and new measurement techniques are clearly needed. Mathematical calculations based on the modified Goldmann equation have been used to estimate uveoscleral outflow in clinical studies..$^{20}$ The main significance of uveoscleral outflow in glaucoma is likely to be the possibility to enhance it and thereby reduce IOP.

A preclinical study in rabbits has indicated that ultrasonic coagulation of the ciliary body using HIFU results in a dual effect on the dynamics of aqueous humour that contributes to an IOP reduction. ${ }^{21}$ The first effect is a reduction in the aqueous humour production via remodelling of the ciliary processes in the pars plicata segment, which has been described as the main mechanism of action. Unlike reduced aqueous production, an increase in the aqueous outflow via the uveoscleral pathway is perhaps a less expected mechanism of action of UCP that nonetheless has been hypothesised on multiple occasions.1112,21-23 Aptel observed in 2014 that a fluid space could be seen between the sclera and the ciliary body, and between the sclera and the choroid adjacent to treated areas, ${ }^{21,24}$ and hypothesised that this corresponds to an area where the opening of the space should lead to an increase of the aqueous outflow via the uveoscleral pathway. A more recent prospective, observational monocentric study from Rouland and Aptel, using three-dimensional ultrasound biomicroscopy (UBM) that included 24 eyes from 19 patients, demonstrated that, in addition to reduction in aqueous humour production, UCP treatment caused an increase in aqueous humour outflow due to uveoscleral pathway opening. ${ }^{25}$ Increased uveoscleral outflow has also been demonstrated in monkeys following diode laser TSCPC applied to the pars plana of the ciliary body. ${ }^{26,27}$ Further, uveoscleral outflow enhancement has been suggested to take place after endoscopic cyclophotocoagulation and pars plana ablation (ECP-plus) in patients with refractory glaucoma. ${ }^{28}$

In addition, a study of 44 patients with refractory glaucoma demonstrated that UCP treatment can induce anatomical modifications of the sclera and conjunctiva; this was determined using the anterior segment optical coherence tomography (AS-OCT) and in vivo confocal microscopy (IVCM) ${ }^{29}$ Again, this suggests that enhancement of transscleral aqueous humour outflow is a plausible mechanism by which ultrasound treatment reduces IOP. In this study, a marked increase in intra-scleral hyporeflective spaces (HS) was observed that correlated strongly with IOP reduction. In a recent study, Mastropasqua et al. ${ }^{30}$ hypothesised that the increase of HS may be due to a heating of the suprachoroid, sclera, and conjunctiva during the procedure. This increase in HS within the stroma may increase hydraulic conductivity and enhance the transscleral aqueous humour outflow.

\section{Safety outcomes}

Study evidence suggests that UCP has a favourable safety profile compared with cyclo-destructive methods, with no phthisis bulbi, no induced cataract, and no persistent hypotony. In a recent prospective, observational, monocentric study, which was based on visualisation with 24 eyes from 19 patients, no cyclodialysis cleft has been observed, where atrophy of the ciliary processes and opening of the uveoscleral
Figure 6: Endoscopic visualisation of pig's ciliary body before (A) and during (B) an ultrasound cycloplasty procedure

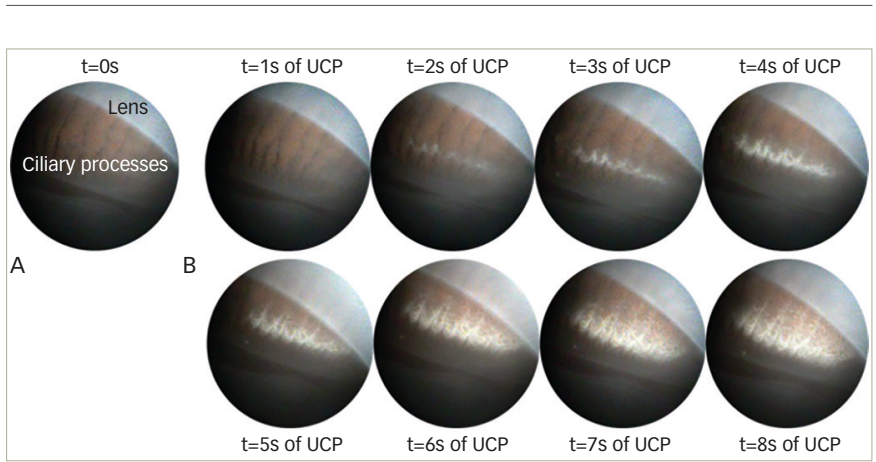

$U C P=$ ultrasound cycloplasty. Reused with permission from EYE TECH CARE.

Figure 7: Thermal modelling of ultrasound cycloplasty versus diode laser treatment

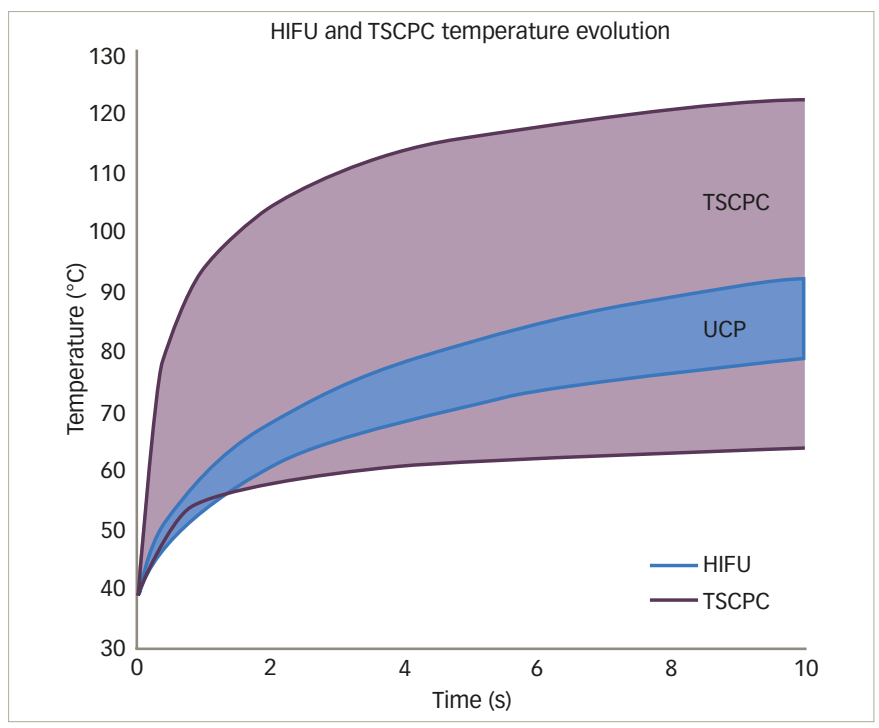

HIFU = high-intensity focused ultrasound; TSCPC = transscleral cyclophotocoagulation; $U C P=$ ultrasound cycloplasty. Reused with permission from EYE TECH CARE.

pathway could clearly been seen..$^{25}$ In this study, systematic preoperative and post-operative visits were held at day 7 , month 1 and month 3 , with IOP measurement and UBM on eight axes (i.e., six ultrasound-treated zones and two non-treated zones).

In a meta-analysis of seven trials, involving 251 patients, that evaluated the efficacy and safety of UCP, scleral marks were observed in 26 patients but, in these patients, no scleral thinning was found on OCT. ${ }^{31}$ Macroscopic observations and histological analysis show some scleral marks on the path of the ultrasound beam and close to the lesion on the ciliary body in a preclinical study (Figure 8). These marks are the consequences of a re-arrangement of the tissue. The composition of these zones of re-arranged tissue is not the same as the normal sclera (in terms of the nature of the collagen, density and orientation of the elastic fibres) and present different elasticity, resistance, permeability and opacity properties. Thus, it is more compact and denser. Its refractive power to light differs from a healthy area which may explain the translucid and greyed appearance observed macroscopically. In terms of potential effects on other structures of the eye, no effects of UCP have been observed on the retinal layers (Figure 8), with no damage apparent on rods, cones, ganglion cell or bipolar cells. In addition, the ultrasound beam is focused on the ciliary body and there is no destructive effect of the UCP procedure on the retinal layers (Figures 8 and 9). 
Figure 8: Low $(40 \mathrm{X})$ and high-magnification $(100 \mathrm{X})$ histologic slices showing details of retinal layers of a pig eye treated with ultrasound cycloplasty
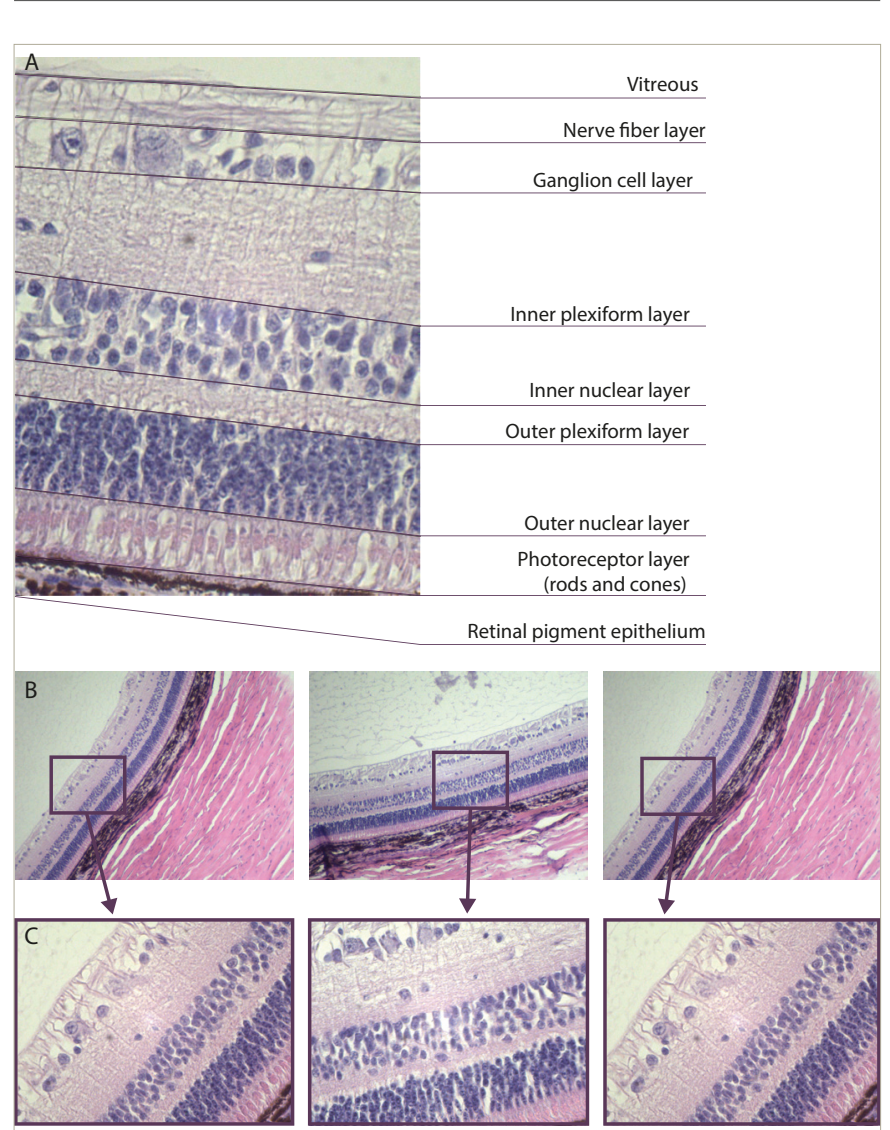

The ultrasound beams, focused on the ciliary body, are safe for retina.

In these pictures after UCP treatment, no disruption of layers can be observed.

$U C P=$ ultrasound cycloplasty. Reused with permission from EYE TECH CARE.

\section{Discussion}

Experience to date shows that UCP provides good efficacy with respect to IOP reduction for the vast majority of patients in the initial 1 week phase of treatment. This is emphasised by a study of 103 patients with refractory and non-refractory glaucoma, in which 94 (91\%) achieved an initial reduction in IOP (data on file, EYE TECH CARE). At 6 months, 64\% of patients had an IOP reduction of $35 \%$. Figure 10 shows these data in a different representation demonstrating how the treatment response separates the 103 patients into three distinct subgroups: in the first phase following the procedure, at day 7, a decrease in IOP from baseline of around $50 \%$ is observed in all three subgroups (from 24.6 to $12.8 \mathrm{mmHg}$ ). In the second phase, a difference in treatment response becomes apparent between the three subgroups during the first 3 months:

1. In 65 patients (63.1\%), treatment success is achieved whereby the IOP remains low.

2. In 22 patients (21.4\%), the IOP immediately rises back to near the original level at 3 months, indicating treatment failure: 'early failure'.

3. In 7 patients (6.8\%), an intermediate response is seen where an initial reduction in IOP is achieved followed by a slow rise in the 6 months following the procedure: 'late failure'. These patients would most probably benefit from a second phase of UCP treatment to increase efficacy and durability of response.

Since IOP decreased in all three subgroups in the initial phase, early or late treatment failure is unlikely to be due to a technical problem, such as incorrect positioning of the probe. Rather, a model is proposed to explain
Figure 9: Low-magnification (40 X) histologic slices showing details of pig's ciliary body treated with ultrasound cycloplasty
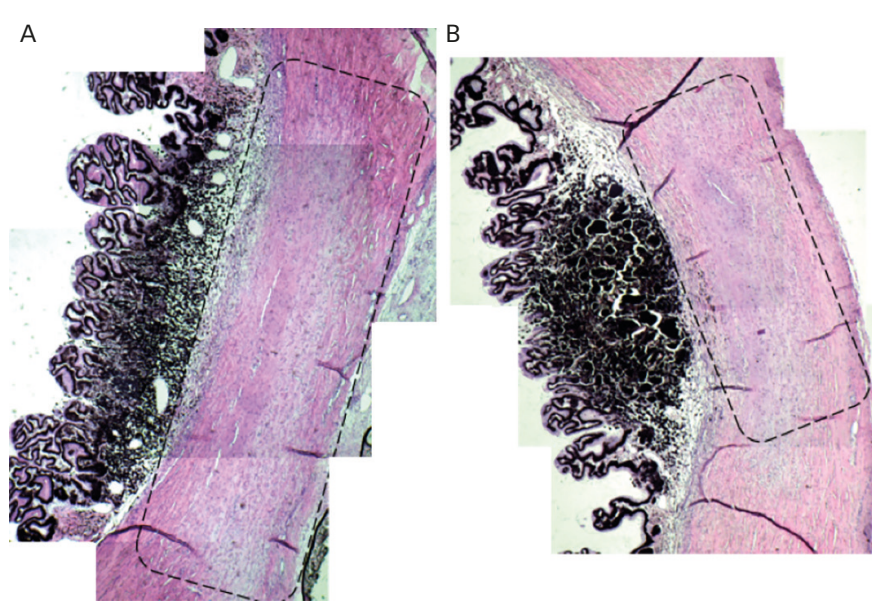

The ultrasound beam passes through the sclera and may remodel the structure (black dotted rectang/e).

Figure 10: Treatment response in intra-ocular pressure among 103 patients who had undergone ultrasound cycloplasty

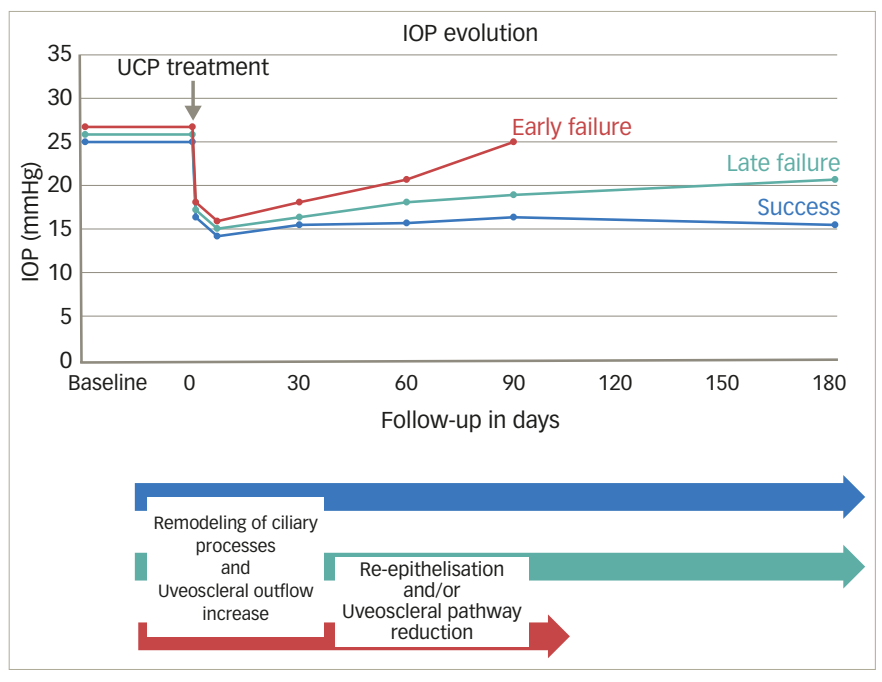

$I O P=$ intraocular pressure; $U C P=$ ultrasound cycloplasty. Reused with permission from EYE TECH CARE.

these observations whereby the differences between patients after the first 3 months may reflect: (i) a reduction in the uveoscleral-transscleral openings in some patients, leading to a rise in the initially decreased IOP; (ii) a possible re-epithelialisation of the ciliary processes; and/or (iii) that the circumference of $160^{\circ}$ treated might be insufficient for some patients.

The phenomenon of epithelial regeneration has been seen on the ciliary body epithelium of young rabbits, a species known for fast recovery (Figure 11). The inner epithelial layer, which is the forward prolongation of the sensory retina, is nonpigmented, whereas the outer epithelial layer, an extension of the pigment epithelium of the retina, is pigmented. ${ }^{32}$ The ability of the ciliary epithelium to regenerate, including after diode laser cyclophotocoagulation, has been known for some time. ${ }^{33-35}$ In the case of the 'early failures' (where a rise in IOP occurs within the first 3 months), it is unlikely that the ciliary processes have regenerated already, rather, it is more probable that there was a reduction in uveoscleraltransscleral openings and blood supply relay. For late failures, however, re-epithelialisation may have taken place whereby the epithelial cells have recovered their functions. Re-treatment may be required for such 
Figure 11: Low- and high-magnification scanning electron microscopy images of rabbit's ciliary processes undergoing re-epithelialisation
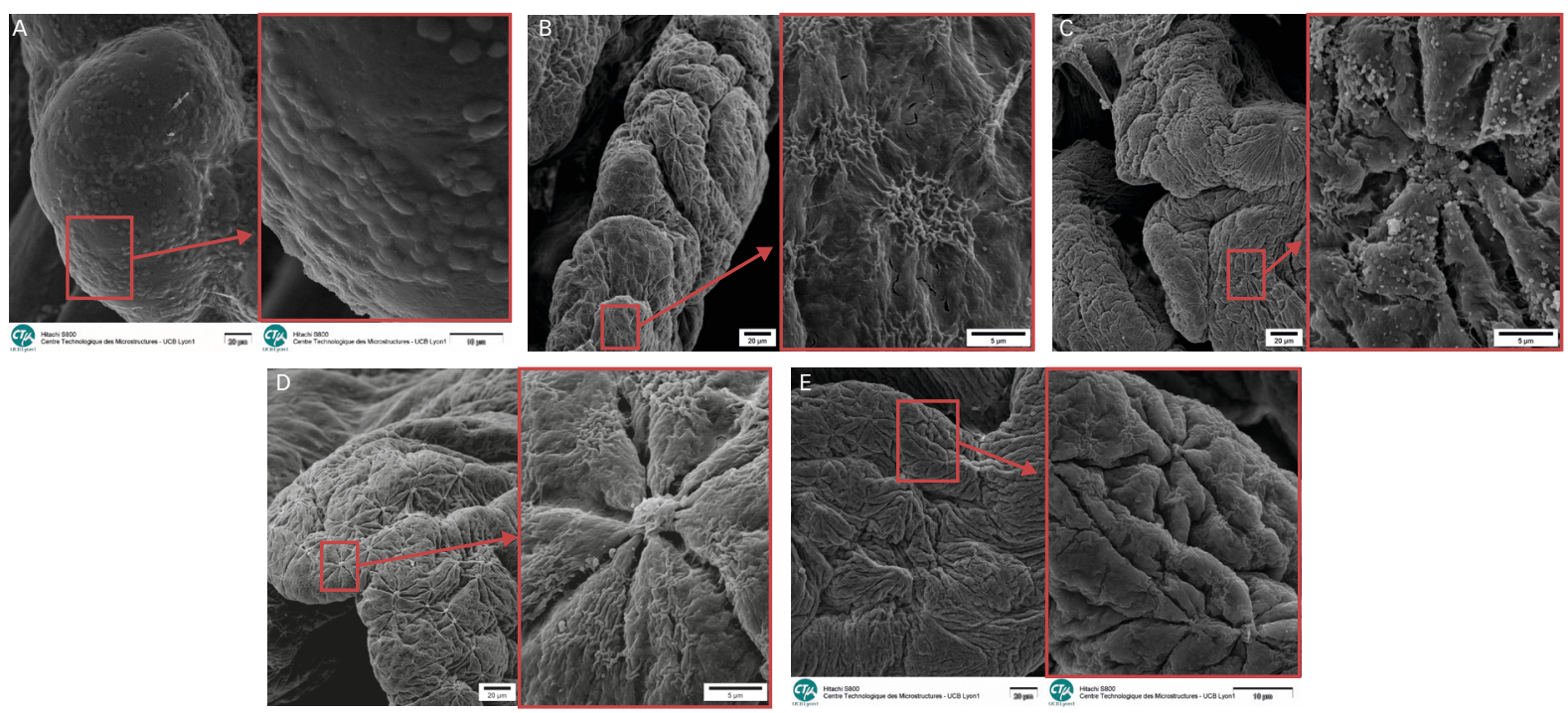

A: Phase 1 (cells bud); B: Phase 2 (beginning of cells clustering); C and D: Phase 3 (cells clustering); E: Phase 4 (re-epithelialisation). Reused with permission from EYE TECH CARE.

patients. Further investigation is warranted to test this hypothesis, and a fluorophotometry study, with a 1-year follow-up, is currently ongoing in the UK to evaluate the uveoscleral outflow (NCT02839590). The uveoscleral outflow will be estimated by the Goldmann's equation method: $\mathrm{Fu}=\mathrm{F}$ - C(IOP-PV); in a total of 30 patients. In this equation, aqueous humouh flow (F) is measured by fluorophotometry, outflow facility (C) by Schiotz tonographer, IOP by tonometry, and episcleral venous pressure (PV) will be calculated based on each patient's parameters.

\section{Conclusion}

The first 3 months following the UCP procedure are critical in that separation of patients into treatment success or failure occurs at this time. In addition, complications, if they arise, tend to do so within the same timeframe. Particular attention needs to be paid to a minimum baseline IOP of $21 \mathrm{mmHg}$ to avoid the risk of hypotony. Anti-inflammatory treatment is crucial: during the 4 weeks after the UCP procedure steroid agents should be administered. ${ }^{31}$ The UCP procedure remodels the ciliary body, removing the initial epithelial cells layers but leaving the blood-aqueous barrier intact. UCP is not therefore an aggressive or destructive procedure, which explains why re-treatment is feasible in cases where the desired IOP reduction is not reached. UCP is indicated for patients who had filtering surgery and those who are on maximum tolerated medication with a risk of surgical failure. $\square$
Lynn JG, Putnam TJ, Histology of Cerebral Lesions Produced by Focused Ultrasound, Am J Pathol, 1944;20:637-49.

2. Coleman DJ, Lizzi FL, Torpey JH, et al., Treatment of experimental lens capsular tears with intense focused ultrasound, Br J Ophthalmol, 1985;69:645-9.

3. Coleman DJ, Lizzi FL, Driller J, et al., Therapeutic ultrasound in the treatment of glaucoma. II. Clinical applications, Ophthalmology, 1985;92:347-53.

4. Coleman DJ, Lizzi FL, el-Mofty AA, et al., Ultrasonically accelerated resorption of vitreous membranes, Am J Ophthalmol, 1980;89:490-9.

5. Rosenberg RS, Purnell EW, Effects of ultrasonic radiation to the ciliary body, Am J Ophthalmol, 1967;63:403-9.

6. Silverman RH, Vogelsang B, Rondeau MJ, et al., Therapeutic ultrasound for the treatment of glaucoma, Am I Ophthalmol, 1991;111:327-37

7. Rosecan LR, Iwamoto T, Rosado A, et al., Therapeutic ultrasound in the treatment of retinal detachment: clinical observations and light and electron microscopy, Retina, 1985;5:115-22.

8. She WH, Cheung TT, Jenkins CR, et al., Clinical applications of high-intensity focused ultrasound, Hong Kong Med J, 2016:22:382-92.

9. Kennedy JE, High-intensity focused ultrasound in the treatment of solid tumours, Nat Rev Cancer, 2005;5:321-7.

10. Focused Ultrasound Foundation (US), Web Page, 2017. Available at: www.fusfoundation.org/the-technology/state-of-thetechnology (accessed 15 June 2017)

11. Aptel F, Charrel T, Palazzi X, et al., Histologic effects of a new device for high-intensity focused ultrasound cyclocoagulation, Invest Ophthalmol Vis Sci, 2010;51:5092-8.

12. Aptel F, Charrel T, Lafon C, et al., Miniaturized high-intensity focused ultrasound device in patients with glaucoma: a clinical pilot study, Invest Ophthalmol Vis Sci, 2011;52:8747-53.

13. Charrel T, Aptel F, Birer A, et al., Development of a miniaturized HIFU device for glaucoma treatment with conformal HIFU device for glaucoma treatment with conformal
coagulation of the ciliary bodies, Ultrasound Med Biol, 2011;37:742-54.
14. Bill $\mathrm{A}$, The aqueous humor drainage mechanism in the cynomolgus monkey (Macaca irus) with evidence for unconventional routes, Invest Ophthalmol, 1965;4:911-9.

15. Bill A, Hellsing K, Production and drainage of aqueous humor in the cynomolgus monkey (Macaca irus), Invest Ophthalmol, in the cynomo

16. Johnson M, MCLaren JW, Overby DR, Unconventional aqueous humor outflow: A review, Exp Eye Res, 2016;158, 94-111.

17. Toris $\mathrm{CB}$, Camras $\mathrm{CB}$, Measuring the outflow of aqueous humo Glaucoma Today, 2007;September/October:15-22. Available at http://glaucomatoday.com/2007/10/GT0907_01.php/ (accessed 13 June 2017).

8. Alm A, Nilsson SF, Uveoscleral outflow--a review, Exp Eye Res, 2009;88:760-8.

19. Nilsson SF, The uveoscleral outflow routes, Eye (Lond), 1997;11 (Pt 2):149-54

20. Fautsch MP, Johnson DH, Aqueous humor outflow: what do we know? Where will it lead us?, Invest Ophthalmol Vis Sci, 2006:47:4181-7.

21. Aptel F, Begle A, Razavi A, et al., Short- and long-term effects on the ciliary body and the aqueous outflow pathways of highintensity focused ultrasound cyclocoagulation, Ultrasound Med Biol, 2014:40:2096-106.

22. Denis $P$, Aptel F, Rouland JF, et al., Cyclocoagulation of the ciliary bodies by high-intensity focused ultrasound: a 12-month multicenter study, Invest Ophthalmol Vis Sci, 2015;56:1089-96.

23. Aptel F, Dupuy C, Rouland JF, Treatment of refractory open-angle glaucoma using ultrasonic circular cyclocoagulation: a prospective case series, Curr Med Res Opin, 2014;30:1599-605.

24. Aptel F, Ultrasonic Circular Cyclocoagulation. In Samples JRA, Ahmed III (eds.), Surgical Innovations in Glaucoma, New York, US: Springer, 2014;113-27.

25. UBM evaluation after ultrasound ciliary plasty with high intensity focused ultrasound, towards a new explanation of the uveoscleral pathway. Presented at: French Society of Ophthalmology 123rd Congress (SFO), 6-9 May 2017.
26. Ho CL, Wong EY, Chew PT, Effect of diode laser contact transscleral pars plana photocoagulation on intraocular pressure in glaucoma, Clin Exp Ophthalmol, 2002;30:343-7.

27. Liu GJ, Mizukawa A, Okisaka S, Mechanism of intraocular pressure decrease after contact transscleral continuouswave Nd:YAG laser cyclophotocoagulation, Ophthalmic Res, 1994;26:65-79

28. Tan JC, Francis BA, Noecker R, et al., Endoscopic Cyclophotocoagulation and Pars Plana Ablation (ECP-plus) to Treat Refractory Glaucoma, I Glaucoma, 2016;25:e117-22.

29. Mastropasqua R, Agnifili L, Fasanella V, et al., Uveo-scleral outflow pathways after ultrasonic cyclocoagulation in refractory glaucoma: an anterior segment optical coherence tomography and in vivo confocal study, Br J Ophthalmol, 2016;100:1668-75.

30. Mastropasqua R, Fasanella V, Mastropasqua A, et al., Highintensity focused ultrasound circular cyclocoagulation in glaucoma: a step forward for cyclodestruction?, J Ophthalmo 2017;2017:7136275.

31. Denis $\mathrm{P}$, Clinical Research of Ultrasound Ciliary Plasty and Implications for Clinical Practice, European Ophthalmic Review. 2016;10:108-12.

32. Duke-Elder $\mathrm{S}$, The anatomy of the visual system. In Duke-Elder $\mathrm{S}$ (eds.), System of Ophthalmology, London, UK: Henry Kimpton, 1961;146-8.

33. Yamashita $\mathrm{H}$, Sears $\mathrm{M}$, Proof that the ciliary epithelium can regenerate, Exp Eye Res, 1978;27:199-213.

34. Walland MJ, Diode laser cyclophotocoagulation: dosestandardized therapy in end-stage glaucoma, Aust N Z Ophthalmol, 1998;26:135-9.

35. McKelvie PA, Walland MJ, Pathology of cyclodiode laser: a series of nine enucleated eyes, Br J Ophthalmol, 2002;86:381-6.

36. Dürr U, Henchoz PD, Fankhauser F, Kwasniewska S, Results and methods of transscleral cyclodestruction - A new contact lens for use with non-contact systems, Lasers Light ophthalmol, 1990;3:123-13. 